\title{
Rule Talk: Instructing Proper Play With Impersonal Deontic Statements
}

\author{
Jörg Zinken ${ }^{1 *}$, Julia Kaiser ${ }^{1}$, Matylda Weidner ${ }^{2}$, Lorenza Mondada ${ }^{3}$, Giovanni Rossi ${ }^{4}$ and \\ Marja-Leena Sorjonen ${ }^{5}$ \\ ${ }^{1}$ Department of Pragmatics, Leibniz-Institute for the German Language, Mannheim, Germany, ${ }^{2}$ Department of English Linguistics, \\ Kazimierz Wielki University, Bydgoszcz, Poland, ${ }^{3}$ Department of Languages and Literatures, University of Basel, Basel, \\ Switzerland, ${ }^{4}$ Department of Sociology, University of California, Los Angeles, Los Angeles, CA, United States, ${ }^{5}$ Department of \\ Finnish, Finno-Ugrian and Scandinavian Studies, University of Helsinki, Helsinki, Finland
}

\section{OPEN ACCESS}

Edited by:

Xiaoting $\mathrm{Li}$,

University of Alberta, Canada

Reviewed by:

Melisa Stevanovic,

University of Helsinki, Finland

Emily Hofstetter,

Linköping University, Sweden

${ }^{*}$ Correspondence:

Jörg Zinken

zinken@ids-mannheim.de

Specialty section:

This article was submitted to

Language Sciences,

a section of the journal

Frontiers in Communication

Received: 29 January 2021 Accepted: 22 June 2021

Published: 23 July 2021

Citation:

Zinken J, Kaiser J, Weidner M, Mondada L, Rossi G and Sorjonen M-L (2021) Rule Talk: Instructing Proper

Play With Impersonal

Deontic Statements.

Front. Commun. 6:660394. doi: $10.3389 /$ fcomm.2021.660394
The present paper explores how rules are enforced and talked about in everyday life. Drawing on a corpus of board game recordings across European languages, we identify a sequential and praxeological context for rule talk. After a game rule is breached, a participant enforces proper play and then formulates a rule with an impersonal deontic statement (e.g. "It's not allowed to do this"). Impersonal deontic statements express what may or may not be done without tying the obligation to a particular individual. Our analysis shows that such statements are used as part of multi-unit and multi-modal turns where rule talk is accomplished through both grammatical and embodied means. Impersonal deontic statements serve multiple interactional goals: they account for having changed another's behavior in the moment and at the same time impart knowledge for the future. We refer to this complex action as an "instruction." The results of this study advance our understanding of rules and rule-following in everyday life, and of how resources of language and the body are combined to enforce and formulate rules.

Keywords: accountability, conversation analysis, rules, deontic modality, multi-modality, instruction, impersonal structures

\section{INTRODUCTION}

Rules are ubiquitous in our social lives, from traffic lights to taxation, from cooking to queuing. Rulefollowing is so fundamental to human behavior that it has become a metaphor for scientific understanding of some of our most impressive human skills (Erickson et al., 2013): The rules of rational behavior, the rules of making judgments under uncertainty, the rules of grammar, or indeed, the rules of conversational turn-taking. Internalized rules, however, cannot alone generate proper conduct, because they cannot create the contexts of their application (Wittgenstein 1953; Garfinkel 1967). This raises the question of how human actors draw on rules as part of making sense of local situations, and how they come to agree that some locally implemented way of acting follows a rule (Liberman 2013, ch. 3).

The present study is part of a larger project on rules and rule-following in various everyday activities across languages. As part of that project, we examine moments in which a person intervenes to halt another person's action. Our focus here is on interventions that take place during board games, and particularly after a player has acted in violation of a game rule. The activity of playing a board game unfolds in the here and now, turn by turn, move by move. Yet games are constituted by rules that hold beyond the here and now. During board games, players 
closely monitor one another's moves, including for whether or not they are in accordance with the rules. Board games are therefore a particularly rich source of insight into rules and rule-following in social interaction (see also Hofstetter and Robles 2019).

Among the communicative resources that players have to formulate rules, we are especially interested in impersonal deontic statements (e.g. "It's not allowed to do this," "It's necessary to do that"), a practice of speaking that we find recurrently in the context of rule breaches. Prima facie, impersonal deontic statements are a prime resource for connecting particular game moves to codified game rules-to "what one must and mustn't do." After all, game rules apply to anyone playing the game, and impersonal constructions are a uniquely suited means for such generic reference. Also, game rules specify what are valid or allowable moves in a game, and deontic structures centrally express meanings of obligation and permission. As we will see, however, players do not formulate the game rules using impersonal deontic statements every time that a rule is violated. These constructions are instead specifically used to instruct a player who is treated as having insufficient knowledge of the rules.

The aim of the paper is twofold: Firstly, to show how impersonal deontic statements are used in the context of rule violations in concert with the praxeological and embodied detail of the ongoing course of action. Secondly, to demonstrate that a positionally sensitive and multimodal analysis of grammar can further our understanding of invariances in the meaning of impersonal deontic statements, as well as of their functional versatility as a practice for "rule talk." Our main path towards these goals will be to document how impersonal deontic grammar systematically co-occurs with recognizable forms of embodied conduct. Together, grammar and embodied conduct imbue an instruction with the authority of a rule.

Linguists study a diverse range of phenomena under the rubric of impersonality (for overviews: Siewierska 2008; Malchukov and Siewierska 2011). Examples include "meteo-verbs" (such as Russian temneet, "it is getting dark"), "locative subject" constructions (the garden is swarming with bees), and subjectless constructions, such as the Polish -no/-to construction (tutaj tańczono, "dancing took place here," "some people danced here"), to name just a few. Unsurprisingly, a recurrent topic in the literature is the quest for order in the impersonal domain. Some researchers define impersonality in terms of linguistic form, and view the core of the category as constituted by (operations on) argument structure, specifically by a departure from canonical subjecthood. Other researchers, often arguing from a cognitive-linguistic standpoint, treat impersonality as a matter of semantic or discourse choices that background the agent in, or the "instigator" of, an event. These differences in the conceptualization of impersonality have been summarized as a subject-centered and an agentcentered perspective on impersonality (Siewierska 2008). The two perspectives differ in the ways they define the outer limits of impersonality as a linguistic category. For example, the Russian unaccusative sentence in (1) below, although "personal" in the sense that it involves an experiencing person, can be considered impersonal from a subjectcentered perspective, because the subject is noncanonically marked, with dative case (Schlund 2018, p. 124).

(1) mne bylo grustno

me.DAT was.3SG.NEUTR sad

I was sad

An anticausative sentence such as $(2 \mathrm{a})$, on the other hand, would not be considered impersonal from the subject-centered perspective, as it contains a nominative subject and an agreeing predicate. It could, however, be considered impersonal from the agent-centered perspective, if it is taken to be selected over an alternative (such as $2 \mathrm{~b}$ ) as a way of backgrounding the instigator (Siewierska 2008, p. 124).

(2a) The vase broke

(2b) Jim broke the vase

An important concern in the literature then has been how to define the boundaries of the category of impersonality in terms of shared features. What emerges from this literature, however, is a very broad and heterogeneous category. The present study contributes to our understanding of impersonality by re-connecting impersonal grammar with its utility in social interaction. Firstly, it begins not with a general definition of "impersonality," but from a type of event-the violation and enforcement of a game rule-in which we recurrently find constructions that fall into the category of impersonality from both the subject-centered and agent-centered perspective. Our point of departure are deontic statements that describe a norm pertaining to a human referent, who is, however, not expressed as a canonical subject. (3) is an example from Italian, where the subject is expressed non-pronominally with a reflexive marker expressing generic human agency (Giacalone Ramat and Sansò, 2011, see Ex. 4 below).

\section{(3) non si pu-ò di-re}

NEG REFL can-3SG say-INF

"it is not allowed to say"/"one cannot say"

Secondly, our approach is to use episodes of rule violation to explore how speakers of different languages employ diverse grammatical structures as well as embodied means to achieve what may be regarded as the quintessential purpose of an impersonal deontic statement: the formulation of a rule.

Impersonal structures have a natural affinity with deontic meanings when it comes to the formulation of rules and norms (Gast and van der Auwera 2013). In fact, the "impersonal" reference of a linguistic structure can result from the deontic meaning of the utterance. Consider the "generic you," a crosslinguistically attested method for achieving "reference impersonality" (Malchukov and Ogawa 2011), that is, for 
talking about events that require a human participant without referring to anybody in particular. The generic reading of this pronoun seems to be closely connected to the formulation of norms or rules, as in the Ten Commandments (e.g., thou shalt not murder) (see Bolinger 1979; Orvell et al., 2017; Stukenbrock 2017; Auer and Stukenbrock 2018, p. 302). Likewise, a modal structure might on occasion take on a deontic meaning in a context of "generality." For example, some of the languages in our corpus have a modal verb that specifically encodes deontic meanings of permissibility (e.g. Finnish saada, German dürfen or Polish wolno). In these same languages, however, deontic meanings are also often expressed with more generic verbs that cover other modal meanings such as ability and circumstantiality (e.g. German können). And in fact, such generic verbs are the main tool for expressing deontic meanings in languages like Italian and French (potere, pouvoir). We suggest that one way in which these verbs take on a deontic meaning is through their use to accomplish "rule talk," where the speaker voices and enacts a rule that transcends the here and now, and that applies beyond the current participants, to anyone playing the game. As we will see, this is achieved not by grammar alone, but by an arrangement of linguistic and embodied resources. By examining the sequential development and organization of these episodes of "rule talk," we also show how the impersonality of an impersonal deontic statement is manifested and reified in social interaction.

\section{MATERIALS AND METHODS}

The data for this study come from the Parallel European Corpus of Informal Interaction (PECII), a video corpus that was designed to include the same mundane activities in different European languages, currently French, German, Italian, and Polish, to a smaller extent Finnish, and in the future, British English (Sorjonen et al., 2018; Zinken et al., 2018). Across the languages, we made video recordings of three comparable settings and activities: friends on a relatively long car drive, families having breakfast at the weekend, and friends or relatives playing board games. For all settings, we specified recording criteria that maximize the comparability of data. For example, the game recordings involved tabletop games, four players, and each of them must have played the game before. At the same time, it was important for us to collect authentic data: The recorded events would have taken place anyway, as opposed to being staged for the sole purpose of being recorded.

The present study draws on the board game recordings. It focuses on a type of sequential context that is recurrent in and across these recordings: One player violates a game rule, or is about to do so, and this leads to another player halting the in-progress game move. In a collection of about 50 cases, we noticed that across languages, such sequences often contain impersonal deontic statements, similar to (3) above. We analyzed each single case in great detail, following the methods of Conversation Analysis (Sidnell and Stivers 2013). In the process of developing generalizations, we also considered impersonal deontic statements in other game situations, as well as similar situations of rule violation in which no impersonal deontic statement was used.

Data are transcribed according to conversation-analytic conventions (Jefferson 2004). We provide simplified interlinear glosses for focal transcript lines only. Aspects of embodied conduct are transcribed according to the conventions developed by Mondada (2014). We used ELAN to aid multimodal analysis (ELAN, 2020).

\section{RESULTS}

Impersonal deontic statements are commonly used after a rule violation has been flagged, and the rule violator has discontinued or, where relevant, retracted the breaching move. Below is a first example from Italian. Four friends are playing Dixit. In this game, one player comes up with a word or expression and all the other players then select a picture card from their hand that could fit that phrase. Here, it is Furio's turn to propose the phrase ying e yang ("ying and yang") (lines 1 to 7 are concerned with the pronunciation of this expression). Sofia seeks more explanation of the expression ying $e$ yang by asking in che senso ("in what sense," line 8). Furio responds by raising his eyebrows and opening his palms, indicating that he will not provide any additional details (Figure 1A). Alba, on the other hand, begins a turn that projectably will give a hint (line 9), accompanied by a depictive hand gesture (see Figure 1A).

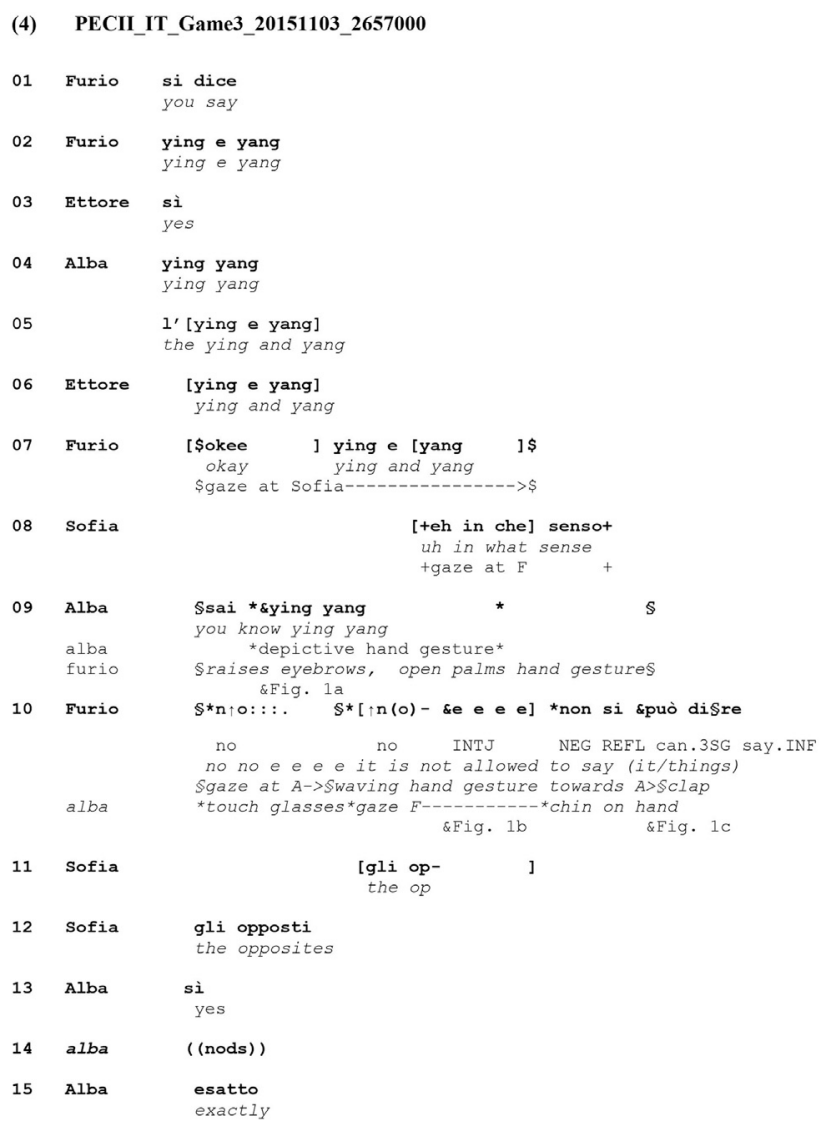




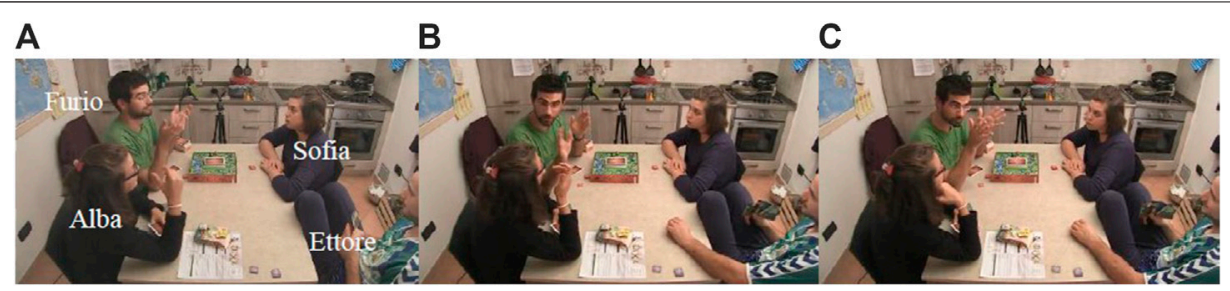

FIGURE 1 |Frames from Extract (4). (A) Alba helps, Furio doesn't, in response to Sofia's question (line 9). (B) Furio intervenes to stop Alba helping Sofia (line 10). (C) Furio turns to Ettore during impersonal TCU (ine 10).

(5)

\section{PECII_FR_Game2_1849000}

1 BER et tu veux pas garder tes trucs, et construire plutôt and don't you want to keep your stuff and rather build

2

une ville au port?

a town at the port?

$3 \quad(0.7)$

4 GIL *ben elle a pas l'droit, * i faut qu'elle PTCL she has NEG ART.right it need.3SG that she well she has not the right, it has to be that she *.............. points with 2 fingers-->

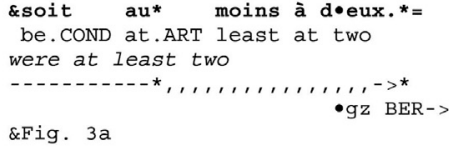

ouais• +il faut être $t+\&$ oujours à +deux.+

yes it need.3SG be.INF always at two

=yeah it always has to be two

Gil $\quad-\rightarrow \bullet$

Jer $\quad+\ldots \ldots \ldots \ldots \ldots$ tpoints---+, $, \ldots,+$

$\& \mathrm{Fig} 3 \mathrm{~b}$

7 GIL =>deux routes.<

$=>$ two roadse

8 JER + [ (pour +garder +les carrtés)]

(in order to defend the squares)

$+\ldots \ldots$. points $+, \ldots, \ldots$, ,

9 BER [ah (bon) • ah ] oui.h

gil oh $($ good $)$ o o yes

$10 \quad(1.0)$

11 JER du coup t'as fini florence?

so have you finished florence

$12 \quad(0.3)$

13 FLO oui

yes

Furio's turn at line 10 has the immediate effect of stopping Alba's emerging assistance. Part of that turn is an impersonal deontic statement, non si può dire, which articulates a prohibition to give verbal hints.

Our initial sense might be that the impersonal non si può dire here simply serves to enforce the relevant game rule. However, a closer look reveals that what Furio does is more subtle and complex than this, which in turn allows us to describe the usage and meaning of the impersonal statement in greater detail. Furio's turn at line 10 is composed of several turn-constructional units (TCUs). First, Furio turns his head towards Alba and halts her attempt to assist Sofia with a prosodically accentuated no:::. (loud, high-pitched, and prolonged), gazing at her, stretching his right arm out towards her, with raised eyebrows (Figure 1B). When Furio begins his no:::., Alba moves her gesturing hand back for a "self-grooming" gesture, adjusting her glasses, and she does not continue her turn (cf. Lerner and Raymond 2017). Then, Furio moves into a second TCU, which begins with a possible second no, and then becomes a multiple prohibitive interjection e e e e (on multiple sayings, see Stivers 2004), accompanied by hand waving and further eyebrow raising. At the beginning of this TCU, Alba turns her head towards Furio, and thus leaves the participation framework with Sofia. So far then, Furio's turn has been specifically addressed, by gaze, to rule-infringing Alba, and Alba has stopped giving assistance to Sofia: she has retracted her gesturing hand, has terminated her unfolding speaking turn, and has turned her gaze away. The discontinuation of an action that was recognizable as an emerging rule-violation has, at this particular moment, been effected; the rule has been enforced.

It is only now that Furio articulates the impersonal unit, the third TCU in his turn, non si puo dire ("it is not allowed to say (it/things)"). This segment of his turn has a multimodal design quite unlike the earlier units. Firstly, it is markedly quieter: there is a very big drop in pitch and loudness relative to what came before (see Figure 2).

Also, during the first items of this TCU (non si), Furio gazes away from Alba and towards the fourth player, Ettore-who has had no role at all so far in this stretch of interaction (Figure 1C) - and then to Sofia. By gazing at Ettore and Sofia during the production of the impersonal TCU, Furio addresses the rule formulation to all players. Latched onto the completion of dire, Furio claps his hands.

The following picture emerges from this more detailed analysis of what Furio does during and around the impersonal TCU non si può dire "it is not allowed to say (it/things)." His impersonal deontic statement is not used to enforce the game rule. Instead, it comes after 
Furio has successfully halted a first infringement of the rule. ${ }^{1}$ An impersonal deontic statement in this position effectively closes the rule enforcement sequence, offering an account for it. But what else does an impersonal deontic statement do here? As we show in the remainder of the paper, impersonal deontic statements treat the would-be rule violator as lacking relevant knowledge of the game rules. The statement supplies this knowledge and imparts it to the players. In this way, the statement functions both as an account for having enforced the rule and as an injunction for the rule to be complied with in the future. In other words, the impersonal deontic statement instructs proper play.

The next three cases (5)-(7) provide support for the analysis 1) that impersonal deontic statements account for rule enforcements by treating the relevant player as lacking relevant knowledge (as opposed to other possible accounts for violating a game rule, such as: the player is trying to cheat, or has forgotten the rule); and 2) that they become recognizable as formulating a general rule through a combination of grammatical and embodied resources. Here is another example. In a game of Settlers of Catan, Bertrand suggests a move to Florence (lines $1-2)$, but this is treated by Gilbert as a violation of a game rule.

\section{(6) PECII IT Game3 201701062033852}

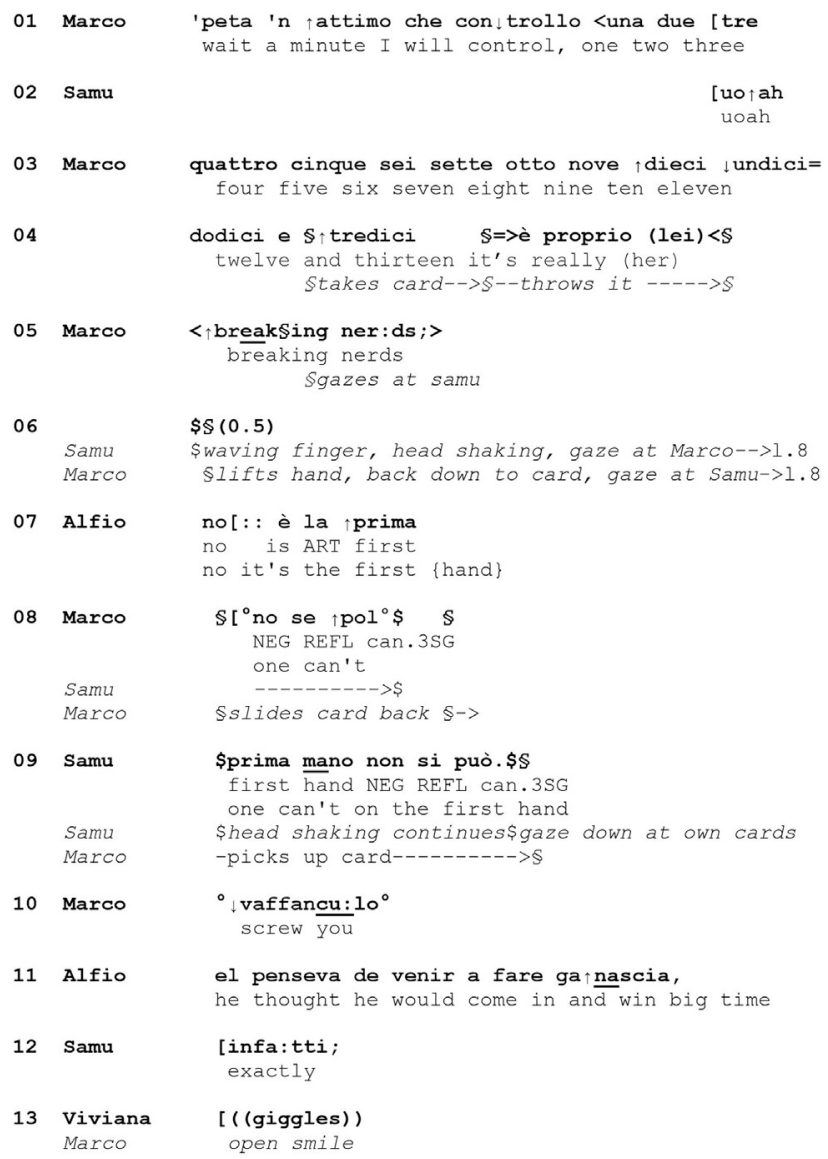

${ }^{1}$ Note that Sofia initiates another assistance seeking sequence in line 13, which Alba briefly completes.

\section{(7a) PECII_DE_Game2_20151113_4206552}

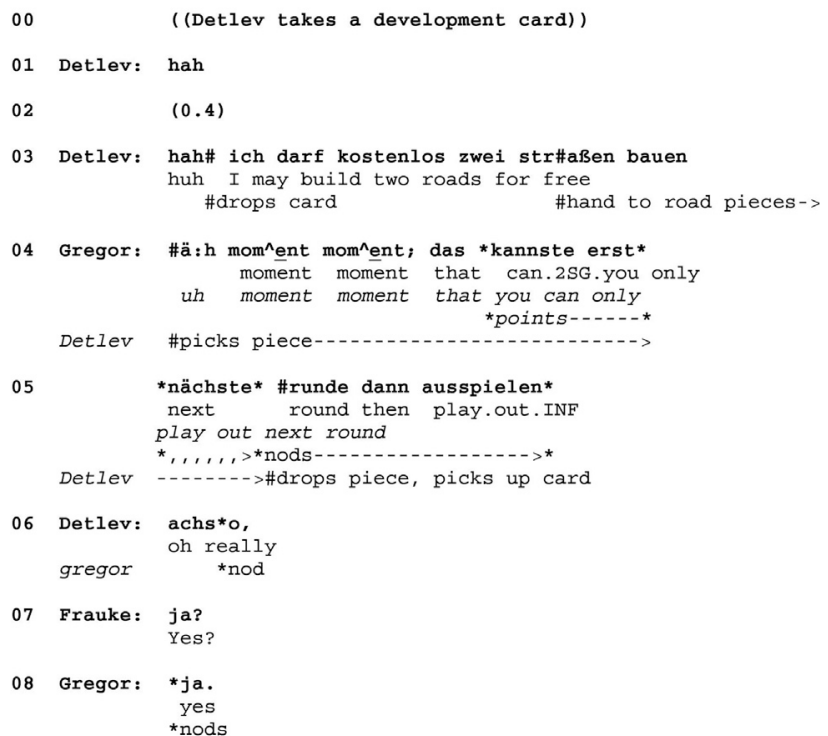

Gilbert intervenes at line 4. Again, as in the previous case, his turn consists of several TCUs. He begins with a stopping move, as we also saw in Ex. 4, in this case, a turn-initial ben, a particle that indicates some reluctance with respect to the previous turn, projecting more to come, potentially disjunctive from what came before (Barnes 1995). His first TCU then formulates a prohibition in a personal format (elle a pas le droit, "she has not the right (to do it)," line 4). This is accompanied by a pointing gesture; a gesture that goes across the board to indicate a precise spot on the board. By the end of this TCU, Gilbert has reached the maximal extension of his pointing gesture, touching the board (Figure 3A). His gesture uses two fingers, possibly indicating the missing two elements he refers to in the next TCU, at the particular spot where the port would be, which makes it impossible for Florence to build a settlement there. Gilbert's next TCU combines an initial impersonal construction (il faut) with a personal pronoun (elle). By the end of this TCU, Gilbert has retracted his gesturing arm-so that the "mixed" impersonal formulation is not deictically connected to places on the board-and he has turned his gaze to Bertrand, the player who suggested the disallowed move. With this turn, then, Gilbert has specifically addressed Bertrand to point out the here-and-now impossibility of the game move he suggested to Florence.

Jerôme not only agrees with Gilbert but also then formulates the rule in an impersonal format: il faut être toujours à deux ("it always has to be in two," line 6). He uses the same deontic verb falloir, and also a temporal adverb that elaborates on the systematicity of the rule (toujours, "always"). As he produces this TCU, he traces the shape of two roads on the table in front of him, thus detaching the rule in his embodied conduct, as we also saw in Ex. 4, from the here-and-now situation of Florence's two roads (Figure 3B). Whereas Gilbert formulated a rule that specifically addressed Florence's particular move, referring to her in the third person, Jerôme aligns with him by formulating the rule in its generality, abstracted from the local circumstances. Bertrand responds with a change-of-state token indicating a realization that his earlier suggestion was inadequate (ah oui, "oh yes," line 9) (Persson 


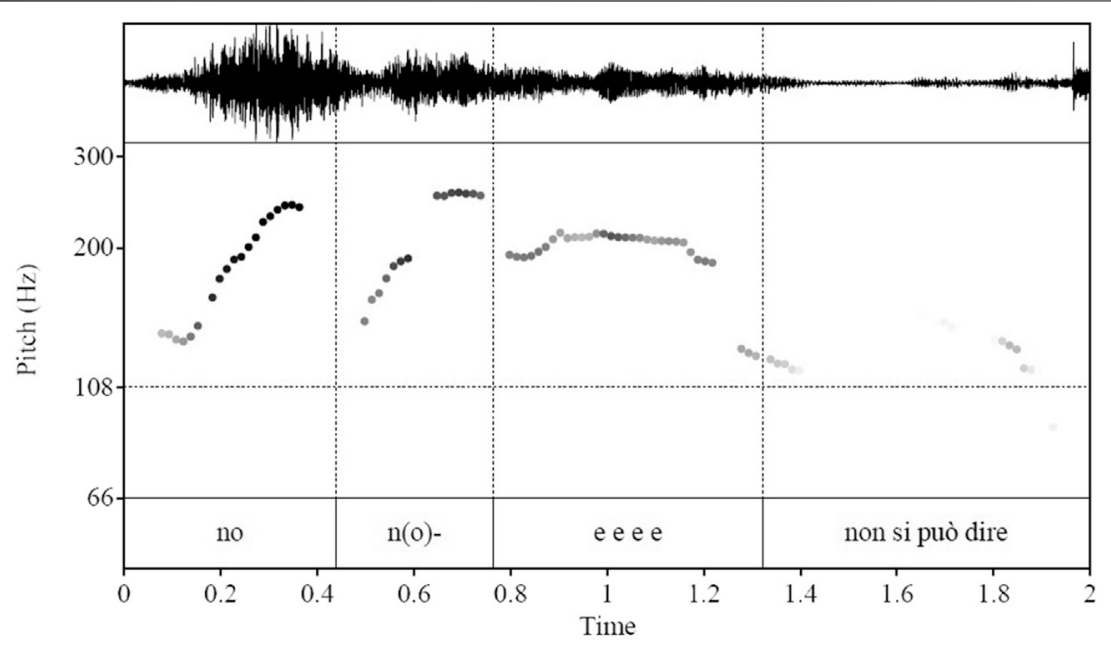

FIGURE $\mathbf{2}$ | The pitch contour of Furio's turn (4. line 11).

2015; see also Heritage 1984), thereby aligning as a now-instructed recipient of the rule-and positioning himself as somebody who did not know that rule.

Here is one more case supporting the analysis that impersonal deontic statements treat a rule infringement as accountable on the grounds that the rule violator did not know the relevant rule. In this next Extract from Italian, four friends are playing the card game Hearts. Marco begins his move by announcing that he needs to check his cards, which he then does by counting out loud the cards on his hand (lines 1-4). As he comes to the end of this counting, he picks the card he wants to play next (see line 4). His next TCU, è proprio (lei) ("it's really (her)," line 4) accompanies his throwing the card. In sum, Marco has "performed” playing a powerful card. He moves into a next TCU as the card is visible on the table, announcing the significance of his move, breaking nerds ("breaking hearts" is a move in this game, Marco seems to be saying breaking nerds, possibly teasing his co-players). At this moment, Samu and Alfio intervene (lines 6 and 7).

(7b) PECII_DE_Game2_20151113_4206552

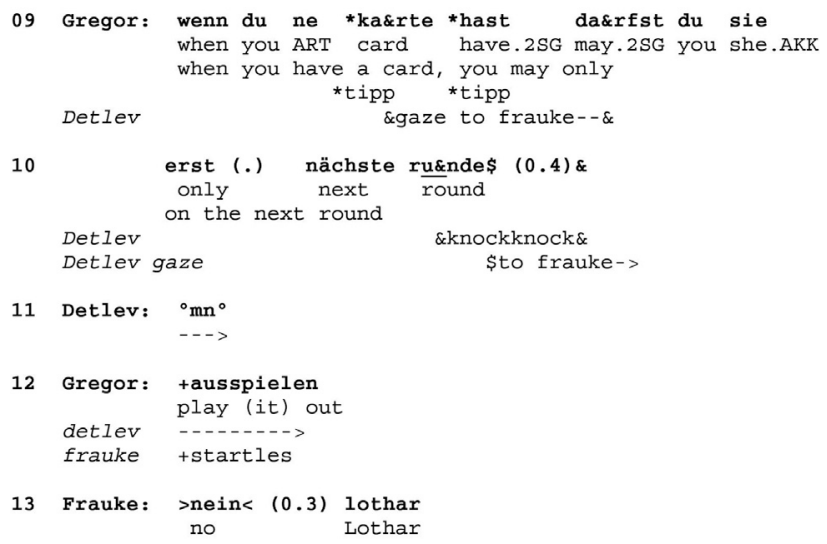

Samu has been drinking from his bottle of beer when Marco was making his game move, and this might explain why he initially responds nonverbally: wagging his finger and shaking his head at Marco (line 6). Marco had begun to lift his arm (the one he had used to throw the card) as part of moving back in his chair, but immediately (after Samu's second finger wag) moves his arm back to the table and begins sliding the card he played back as part of his move of taking it back on his hand. As Marco just reaches the card, Alfio begins a turn (at line 7) that starts with a negation/ prohibition (no::, "no"), and continues with a second TCU, è la prima ("it is the first," line 7). This factual declarative points to a here-and-now state of affairs, and leaves the violated rule to be inferred (cf. Rossi 2018). By this time, Marco has moved his card back from the centre of the table to his corner, and has thus complied with the rule enforcement.

The factual declarative è la prima ("it is the first") could suffice as a pointer to the relevant rule for somebody who knows the rule. Here, however, the participants do not treat Marco as already having known this rule. In overlap with Alfio's first TCU, no::, Marco himself formulates his now-understanding of his move as disallowed, in an impersonal format (no se pol, "one cannot"/"it is not allowed," line 8). Marco's turn displays that he did not know this rule: he presents this rule as an interpretation of his co-players' conduct and offers it for confirmation. In next position, Samu, having swallowed his beer, fully formulates the relevant rule in an impersonal format (prima mano non si può, "one can't on the first hand," line 9). This combines Marco's deontic formulation-which it thereby confirms-with Alfio's factual declarative, which hinted at the rule. Again, this impersonal rule formulation can account for having blocked Marco's move just now, and it works to instruct a less knowledgeable player for the future.

In the brief sequence that follows, the participants provide particularly vivid support for our analysis that impersonal deontic statements account for a rule infringement, and for the need to enforce the rule, as being the lack of knowledge of the relevant player: Alfio teasingly comments on Marco's move (el penseva de venir a fare ganascia, "he thought he would come in and win big time," line 11), a comment at which the fourth player, Viviana, giggles, and which Samu confirms with a lexically and 
prosodically marked response token, infatti ("exactly," line 12), all of which overtly position Marco as a novice who does not yet properly know the rules.

We have now seen three cases in which a game rule was breached, or a rule violation was emerging. Every time, a coplayer initially intervened in a TCU that was addressed to the relevant co-player: by looking at them, gesturing or referring to them (all three cases), or by pointing to or verbally explaining problems on the game board (Ex. 5). Each time, the 'offending' player terminated (Exs 4 and 5) or retracted (Ex. 6) the problematic game move. This context, in which a rule has been enforced, is where we find impersonal deontic statements used in a further TCU to formulate the rule in general terms, instruct co-players about it, and thereby treat the rule violator as not having known the relevant rule. Having established this sequential context as a natural habitat for impersonal deontic statements in board game interactions, we can now use this as a basis for comparison to observe what (other) kinds of linguistic structures are used for the same function in this situation, within and across languages. Here is a further example, this time from German, in which the linguistic structure employed is not canonically impersonal, but which nevertheless functions, in context, as an impersonal deontic statement. We present this case in two separate fragments. The first (7a) contains the segment where the rule is enforced; the second (7b) contains the noncanonical impersonal deontic statement. As in Ex. 5, the game is Settlers of Catan. Detlev has drawn a resource card which allows him to build two roads (line 3 ). He announces this possibility but, as he picks up the road pieces, Gregor intervenes (line 4).

\section{(8) PECII_DE_Game1 201508202000647}

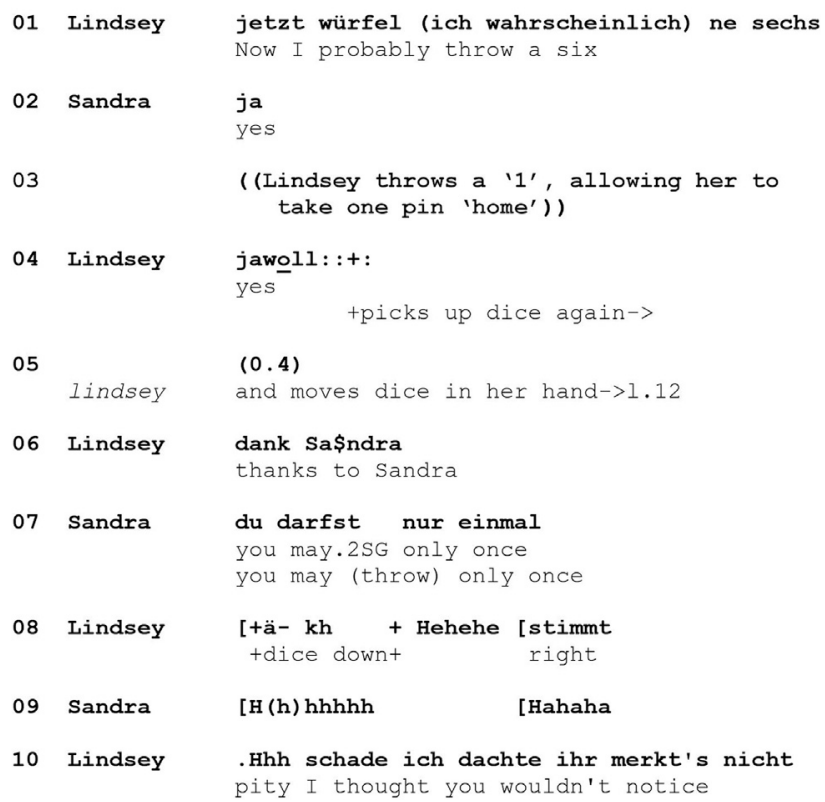

As in the previous cases, the intervention stopping the rule violation is part of a complex turn. Gregor first halts Detlev in a first TCU with äh moment moment ("uh moment moment," line
4). This TCU features marked prosody, with two sharp rise-fall contours. Gregor then moves into a second TCU, which formulates a restriction and addresses it to Detlev with the verb in second person singular, accompanied by a point to Detlev's cards: das kannste erst nächste runde ausspielen ("this you can play out only next round," lines 5-6). Detlev had picked up the road pieces he wanted to use, but he drops them during Gregor's second TCU, on nächste runde (line 5). By the end of Gregor's TCU, then, Detlev has complied with the rule enforcement. In next position, he acquiesces with achso (line 6), conveying his now-understanding of new information (Golato 2010), and thus positioning himself as a player who lacked that knowledge. Frauke produces a "known-answer request for confirmation" (Raymond and Stivers 2016), which can mobilize an account. Gregor minimally but firmly confirms, and then begins his account with a TCU that reformulates his previous restriction as a rule. Here is how the interaction continues.

\section{(9) PECII_PL_Game2_20100122}

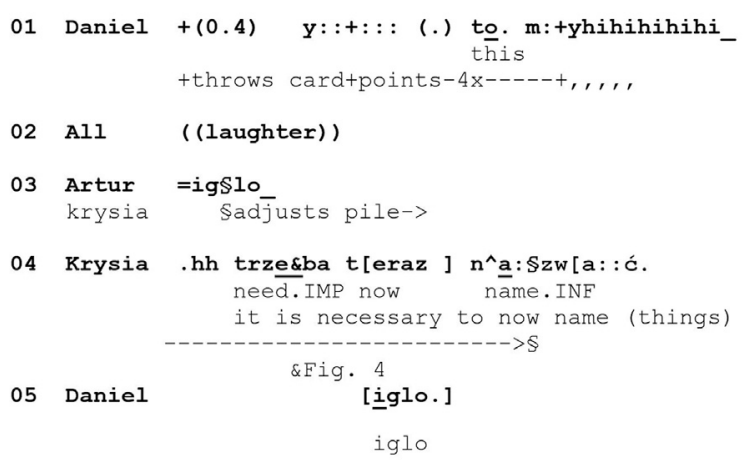

\section{Artur \\ 07 Krysia}

$$
\begin{aligned}
& \text { [nho : :ho: : [ho: : } \\
& \text { yes } \\
& \text { [to: hoho } \\
& \text { 'this' }
\end{aligned}
$$

The second person singular references in Gregor's initial intervention (Ex. 7a) refer to Detlev. Here, on the other hand (Ex. 7b), after a completed rule enforcement, Gregor's second person references (line 9) seem to be generic. The generic reading is favored to an extent by the conditional construction, which abstracts from the local circumstances to contingencies upon which some possibility rests. But as we see in the context of our collection of cases, the local praxeological context, after a rule has been enforced, and after co-players have positioned themselves as not knowing this rule, also invites hearing Gregor's reformulation as an instruction of an "impersonal," or generic rule. While the nächste runde in line 5 (Ex. 7a) is deictic (the next round from now), the nächste runde in line 10 (Ex. $7 \mathrm{~b}$ ) has a relative meaning: any next round after drawing a card. The referent, the card, is referred to deictically in the initial intervention (das, "that," line 5 of (7a)) and accompanied with a deictic pointing gesture, whereas here, in line 9, the card is formulated generically as a type of referent in a lexical noun phrase with indefinite article (ne karte, "a card"). This reference is accompanied by a hand gesture which, however, is not a deictic pointing gesture, but a rhythmic tapping, possibly embodying the "regularity" provided for by the rule-possibly also 


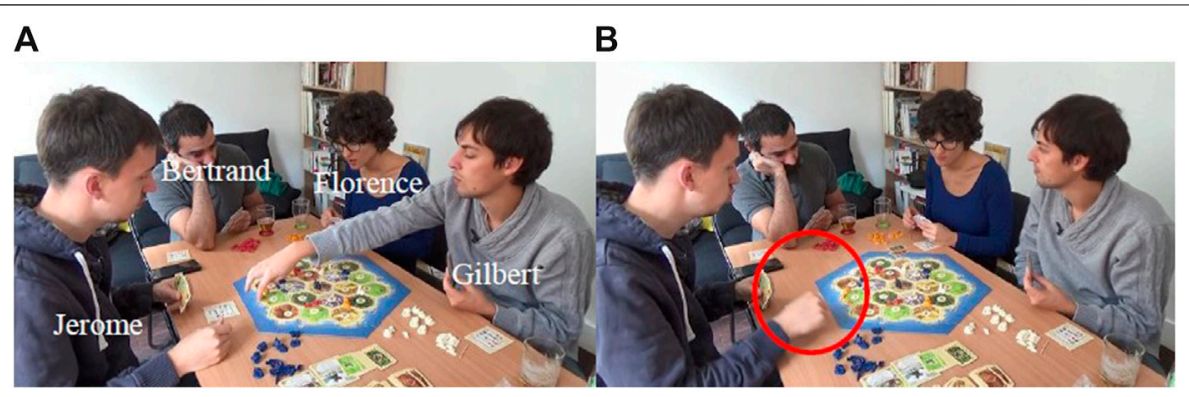

FIGURE 3 | Frames from Extract (5). (A) Gilbert gestures to the place on the board where Florence would build a port (line 4). (B) Jerome gestures a 'distance of two' outside of the board (line 5).

highlighting its obligatory character. Finally, in his initial intervention, Gregor selects the modal verb können (kannste, "you can," line 4), which can have a circumstantial as well as deontic reading. In his generic reformulation, he selects the specifically deontic verb dürfen (darfst, "you may," line 9). In this context then, the $d u$ in line 9 can be taken in a generic or impersonal sense (Gast et al., 2015; Auer and Stukenbrock 2018), whereas the second person singular pronoun $d u$ "you" in line 5 (cliticized to kannst: kannste) referred to Detlev. The impersonal deontic statement here again works as an account for intervening in Detlev's move; again, it occurs after the actual correction has been effected with other, recipient-oriented and personally addressed means; and it treats the offending player as not having known the relevant rule (in fact, in this case, the players explicitly position themselves as not having known this rule, lines 6-7).

In sum, after a rule enforcement has been completed, and the breaching player has complied, impersonal deontic statements formulate a rule as occasioned by, but not restricted to, the local circumstances. Sometimes, we see participants orienting to the fact that the impersonal deontic statement, as opposed to the earlier rule enforcement, does not target the rule violator's here-and-now conduct anymore. In Ex. 4, we saw that Furio moves his gaze away from the rule violator, to the other players, as he moves into the impersonal TCU. In the present case, conduct by the would-be rule violator, Detlev, shows that he does not treat the impersonal deontic statement as now-relevant specifically for him. While Gregor is formulating the deontic impersonal statement, Detlev is already busy with the next steps: he tries to mobilize Frauke to make the next game move, first by briefly gazing at her and an eyebrow flash as Gregor says karte (line 9), and then by gazing to Frauke again and clacking his cards on the table during Gregor's nächste runde (line 10; in response, Frauke startles, line 12).

Let us briefly take stock of our analyses so far. Impersonal deontic statements in the context of emerging rule violations regularly accomplish the social action of instructing rulebreaching co-players about a game rule. The accomplishment of this action rests on a very specific sequential and praxeological context. In this context, the rule violation has already been counter-acted, and the culpable player has complied with a relevant directive. Impersonal deontic statements occur after a (ongoing or projectable) rule violation has been halted with other means. In this context, impersonal deontic statements have a bidirectional character: "Looking back," they furnish an account for the rule enforcement, treating the emerging violation as grounded in a lack of knowledge of the relevant rule. "Looking forward," they are made relevant for all the players for the game "from now on" (see also Liberman 2013, ch. 3). They instruct all players for whom instruction might be relevant, a notion by which we mean imparting actionable knowledge that is relevant beyond the here and now. The sequential habitat of impersonal formulations, at the "exit" of rule enforcement sequences, makes possible this versatility as both an account for something that has just occurred and a directive for what is to happen from now on. It is this complex action that we refer to as an instruction.

In the remainder of this section, we discuss two cases that differ from the pattern we have seen so far. In (8), a rule is enforced after a violation, but no impersonal deontic statement is used. In (9), an impersonal deontic statement is used after a rule violation, but this does not treat lack of knowledge of the rule as the problem. As we will see, these cases ultimately provide additional evidence for our analysis.

In (8), participants account for the rule violation as being due to forgetfulness-and not a lack of knowledge of the rules. Four friends are playing Mensch ärgere dich nicht (similar to Ludo). Lindsey is about to violate a game rule: she has thrown the dice and made her move, but in lines $4-5$ she picks up the dice again and begins moving it in her hand, about to throw again. Sandra intervenes with a restriction in personal format, $d u$ darfst nur einmal ("you may only once," line 7) (note that this so-called "absolute" use of the modal verb, without a predicate such as "throw the dice," works as a possibly complete sentential TCU in German, see Kaiser 2017). In response, Lindsey quickly puts the dice down (line 8).

Initially, things look similar to earlier cases: A player has begun to make a move that violates a game rule (lines 4-5), another player has intervened to enforce the rule (line 7), and the offending player complies with that rule enforcement (line 8). However, Sandra does not formulate the rule in an impersonal format now. Instead, she begins to laugh in overlap with Lindsey's compliance (line 9). The reason seems quite obvious: Lindsey is not in need of instruction, she knows the rule, but made a "mistake." The jerky movement in which she drops the dice, the sound she makes (äh), and her laughter (line 8) seem to embody her sudden realization of her mistake. At line 8, she agrees with Sandra's rule enforcement with stimmt ("right"), conveying that she knows the rule herself but temporarily forgot about it (Betz 2015). Finally, at line 10, Lindsey 
humorously accounts for her move as an attempt to cheat. In sum, two accounts for Lindsey's rule breach are brought into play here-having forgotten and trying to cheat-but not a lack of knowledge of the relevant rule.

Finally, our last case shows that the action of instructing is not inherent in the format of an impersonal deontic statement. Instead, it is the position of a completed rule enforcement that provides the affordance for an impersonal deontic statement to be used in that way. In situations that are slightly different, the claim of a general necessity that is made with an impersonal deontic statement can achieve a different import. In Ex. 9, a player violates a game rule, and a co-player then formulates the relevant rule in an impersonal deontic statement. However, as opposed to earlier cases, the impersonal turn here does not instruct about a game rule that the rule violator did not know. Instead, the impersonal deontic statement makes a moral appeal to the others to stick to the rules from now on. In this extract from a Polish interaction, a group of friends are playing Dobble. The aim of the game is to quickly identify matching pictures on two cards, one on the central pile, and one on the individual players' hands. The player who first names a matching picture can throw the relevant card onto the pile. Here, Daniel flouts the rules by first throwing his card, and then identifying the matching picture in an inappropriate way, using simply the deictic to ("this," line 1), rather than lexically naming the item. Daniel begins to laugh (line 1), and the initial response by all players is to join in laughing (line 2).

The laughter in response to this rule infringement (line 2) does not block Daniel's inappropriate move (as did items such as Italian no:: or German moment = moment in other cases). Rather, it leaves open the possibility that they will let this rule violation pass. Indeed, Artur at line 3 articulates the name of the item that Daniel should have given, iglo. Again, this move does not block or sanction Daniel's move, it does not necessarily halt the game to deal with the infringement, but can instead be taken as helping Daniel out, or doing collaboratively what he should have done. Just after this, Krysia begins to extend her arm with her hand shaped to adjust the pile (Figure 4). Adjusting the pile after each turn, before the next game move is made, is a practice the players established earlier, working as a closing device. So this gesture embodies an orientation to letting the game progress, as opposed to halting it and disallowing Daniel's move (see also Hofstetter 2021).

As Krysia adjusts the pile of cards, she formulates a rule in an impersonal deontic format: trzeba teraz nazwać ("it is necessary to now name (things)," line 4). ${ }^{2}$ Krysia's rule formulation is not a directive to stop and now name the item, but an appeal to do "the naming" from now on. The prosody of nazwać has an appeal/ annoyance quality, in contrast to the impersonal rule formulations we saw earlier. Note also that all impersonal deontic statements in earlier examples were prohibitive ("it is not allowed") or restrictive ("it is only allowed next round"), whereas Krysia's impersonal TCU is a positive statement of necessity. Artur's nho:: in line 6, a confirming particle expressing the self-evident nature of what is

\footnotetext{
${ }^{2}$ Note that in overlap, Daniel draws on Artur's assistance and repeats the name of the item, iglo (line 5), thereby displaying his orientation to the normative expectation that players name the item in their move.
}

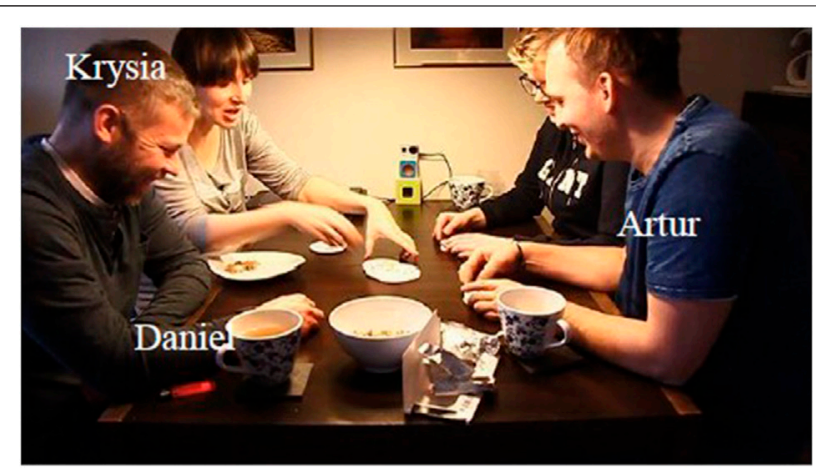

FIGURE 4 | Frames from Extract (9). Krysia adjusts the pile while formulating the impersonal TCU (line 4).

confirmed (Weidner 2018), corroborates the action of chastising Daniel, while also aligning with the decision to let the violation go on this occasion.

So here we have a case where an impersonal deontic statement is used-but not in the context of accounting for a rule violation that was halted and corrected. In this case, the players have chosen not to enforce the rule but to let it pass. By laughing about Daniel's move, all players display an awareness of its rule-bending nature. Earlier in the game, there had been several occurrences of players not properly naming the item but instead simply pointing to it. On those occasions, too, the players let it pass. With the impersonal deontic statement, Krysia takes a stand that this practice should now be terminated. After this fragment, the players in fact do properly name the items, so that it seems that Krysia has been successful in enforcing the rule 'from this point forward'. The moral layer of chastising and appealing in this fragment comes precisely from the leniency that has been extended towards the rule-transgressing Daniel (and players who acted similarly on earlier occasions). As opposed to earlier cases and similarly to the previous Ex. 8, the problem here is not that the culpable player did not know the relevant rule, but that a 'bad practice' had corrupted the game.

\section{DISCUSSION}

In this paper, we have explored how rules are enforced and talked about in everyday life. Drawing on a corpus of board game recordings across European languages, we have identified a sequential and praxeological context for "rule talk": after a game rule is breached, a participant enforces the rule and then formulates it with an impersonal deontic statement (e.g. "It's not allowed to say things"). Impersonal deontic statements express what may or may not be done without tying the obligation to a particular individual. Our analysis shows that such statements are used as part of multi-unit and multi-modal turns where rule talk is accomplished through both grammatical and embodied means.

A focus of our analysis has been on how the action done with an impersonal deontic statement achieves its "impersonality"-how 
speakers accomplish speaking about matters that are valid beyond the current participants (the player who has just violated the rule and the player who has just enforced it) as well as beyond the present moment. We have seen that the generic import of rule instructions is achieved through the arrangement of impersonal grammar with impersonalizing embodied conduct, such as moving from marked to inconspicuous prosody (Ex. 4), gazing away from the here-and-now rule violator to others in the group (Exs 4 and 5), shifting from deictic gestures identifying particular pieces or places on the game board to gestures that are disconnected from it (Exs 5 and 7). Our data show that a reduction in referentiality is not only a grammatically encoded feature of talk ("R-impersonals," see Malchukov and Ogawa 2011), but is systematically accomplished multi-modally with both grammar and the body in social interaction.

We have found impersonal deontic statements to serve multiple interactional goals: they account for correcting another's behavior in the moment and at the same time impart knowledge for the future. In other words, they instruct proper play. By using an impersonal deontic statement, a player rationalizes the enforcement of a rule, imparts the rule to a less knowledgeable player, and ultimately makes the rule public for all. Our analysis is grounded in the details of the sequential and praxeological context in which impersonal deontic statements work as rule instructions, and on the grammatical and multimodal resources with which players accomplish the impersonality that gives a prohibition or postulation the quality of a rule.

We have seen that impersonal deontic statements occur relatively "late," after interventions on a (projectable) rule infringement (sometimes, indeed, in a separate turn, as in Ex. 7). Intervening co-players first enforce the rule with other means. These means range from interjections such as no, Ex. 4, to explicit restrictions such as das kannste erst nächste runde ausspielen ("you can only play this next round," Ex. 7a). What these initial interventions have in common is that they are addressed to the (potential) rule violator: by gaze, by grammar, and/or by manipulating game pieces involved in the rule-violating move. The rule is thus formulated only after the breaching player has complied with the rule enforcement. In that sequential environment, impersonal deontic statements play out their peculiar versatility (Rossi and Zinken 2016): to account for what has happened (what occasioned the rule enforcement) while at the same time directing future action (rule-consistent play). In the overall organization of turns that intervene after a (potential) rule infringement, players thus connect the formulation of a rule to a moment of "entraining" a co-player (what Wittgenstein 1953, called "Abrichtung”). Through this organization, rule formulations become intimately connected to examples of the rule's application.

The present work sheds new light on the notion of "impersonality" in linguistics-a category that is notoriously complex to define, and at times even controversial or confused. ${ }^{3}$ We contribute to the analysis of linguistic impersonality by situating it in a recurrent social habitat for impersonalization across languages. Our approach differs from previous work on impersonal structures,

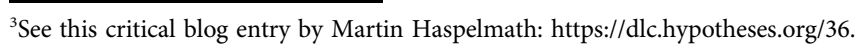

which usually begins by defining "in general" what impersonal language is. "Formal" approaches start from a morpho-syntactic definition based on the lack of a canonical subject; "functional" approaches start from the idea of "agent-defocusing" (Siewierska 2008). Our point of departure is another. We have identified a sequentially and praxeologically delimited "habitat" for impersonalization: the enforcement of a rule that has just been violated. Studying impersonal deontic statements in their habitat makes it possible to situate their meaning in context, explore their functions, and compare them to other constructions in the main arena of their use: speakers' situated social action. This approach does not require us to set the boundaries of the grammatical category in advance. Instead, we begin by observing what kinds of grammatical creatures live in this habitat and use their interactional properties as independent evidence for what belongs in a linguistic category of "impersonality" as it emerges from language use data. Many of the forms we have found across languages would qualify as "impersonal" from any theoretical perspective on impersonality. This applies to the 3rd person singular constructions in Italian and French, where the subject position is occupied with a generic reflexive marker (Italian non si puo, "one cannot") or a dummy pronoun (French il faut, "one must," with the verb falloir that can only be used in the 3rd person singular), as well as to the Polish impersonal trzeba ("one must"), which cannot be combined with a nominative subject. But we have also seen a case with a generic "you" (Ex. 7b), which would not be considered impersonal at least in some subject-centered approaches to impersonality, but which can do just the same work as the more canonically impersonal structures.

Concerning the actions that players accomplish with impersonal deontic statements, we saw that the action of a "rule instruction" is intimately connected to the sequential context where it occurs: after a (potential) rule violation has been halted, and the rule violator has retracted or discontinued their invalid move. In slightly different sequential environments, speakers do not use these constructions or, alternatively, the impersonal deontic statement works differently. For example, if a rule violation is publicly received in a way that does not terminate the invalid move, an impersonal deontic statement can have the meaning of a moral appeal (Ex. 9).

The parallel corpus on which this study is based significantly broadens the possibilities for positionally-sensitive analyses of grammar in embodied social action. The present paper makes this case with an analysis of impersonal deontic statements, which, in a clearly specified position, work as a way to make a rule enforcement socially accountable, while at the same time grounding the rule in a particular example of its application. The results of this study advance our understanding of rules and rule-following in everyday life, and of how resources of language and the body are deployed to carry out social action.

\section{DATA AVAILABILITY STATEMENT}

The datasets presented in this article are not readily available because Data are not presently shared. Requests to access the datasets should be directed to JZ, zinken@ids-mannheim.de. 


\section{ETHICS STATEMENT}

The studies involving human participants were reviewed and approved by the Data protection and ethics committee of participating institutions. The participants provided their written informed consent to participate in this study. Written informed consent was obtained from the individual(s) for the publication of any potentially identifiable images or data included in this article.

\section{AUTHOR CONTRIBUTIONS}

The larger project of which this study is part, including the PECII corpus, was jointly conceived and designed by LM, GR, M-LS, $\mathrm{MW}$, and JZ. All authors participated in data analysis workshops that laid the groundwork for the study. JK, MW, and JZ carried out further data analysis and developed the study. The paper was

\section{REFERENCES}

Auer, P., and Stukenbrock, A. (2018). When 'You' Means 'I': The German 2Nd Ps.Sg. Pronoun Du between Genericity and Subjectivity. Open Linguistics 4 (1), 280-309. doi:10.1515/opli-2018-0015

Barnes, B. K. (1995). Discourse Particles in French Conversation. French Rev. 68 (5), 813-821.

Betz, E. (2015). Indexing Epistemic Access through Different Confirmation Formats: Uses of Responsive (Das) Stimmt in German Interaction. J. Pragmatics 87, 251-266. doi:10.1016/j.pragma.2015.03.018

Bolinger, D. (1979). To Catch a Metaphor: You as Norm. Am. Speech 54 (3), 194. doi:10.2307/454949

ELAN (2020). Nijmegen: Max Planck Institute for Psycholinguistics. https:// archive.mpi.nl/tla/elan.

Erickson, P., Klein, J. L., Daston, L., Lemov, R., Sturm, T., and Gordin, M. D. (2013). How Reason Almost Lost its Mind: The Strange Career of Cold War Rationality. Chicago: University of Chicago Press. http://search.ebscohost.com/ login. aspx?direct $=$ true $\& \mathrm{db}=$ nlebk\&AN=577488\&site $=$ ehost-live\&scope $=$ site.

Garfinkel, H. (1967). Studies in Ethnomethodology. Englewood Cliffs, NJ: Prentice-Hall.

Gast, V., and van der Auwera, J. (2013). "Towards a Distributional Typology of Human Impersonal Pronouns, Based on Data from European Languages," in Languages across Boundaries: Studies in Memory of Anna Siewierska; [On 27 April 2012], the Max Planck Institute for Evolutionary Anthropology in Leipzig ... Organized a One-Day Memorial Workshop. Editors D Bakker and M Haspelmath (Berlin: De Gruyter Mouton), 119-158.

Gast, V., Deringer, L., Haas, F., and Rudolf, O. (2015). Impersonal Uses of the Second Person Singular: A Pragmatic Analysis of Generalization and Empathy Effects. J. Pragmatics 88, 148-162. doi:10.1016/j.pragma.2014.12.009

Giacalone Ramat, A., and Sansò, A. (2011). "From Passive to Impersonal," in Impersonal Constructions: A Cross-Linguistic Perspective, Studies in Language Companion Series 124. Editor A L. Mal'čukov (Amsterdam: Benjamins), 189-228. doi:10.1075/slcs.124.07ram

Golato, A. (2010). Marking Understanding versus Receipting Information in Talk: Achso. And Ach in German Interaction. Discourse Stud. 12 (2), 147-176. doi:10.1177/1461445609356497

Heritage, J. (1984). "A Change-Of-State Token and Aspects of its Sequential Placement," in Structures of Social Action. Editors J. M. Atkinson and J Heritage (Cambridge: Cambridge University Press), 299-345.

Hofstetter, E. (2021). Achieving Preallocation: Turn Transition Practices in Board Games. Discourse Process. 58 (2), 113-133. doi:10.1080/ 0163853X.2020.1816401

Hofstetter, E., and Robles, J. (2019). Manipulation in Board Game Interactions: Being a Sporting Player. Symbolic Interaction 42 (2), 301-320. doi:10.1002/symb.396

Jefferson, G. (2004). "Glossary of Transcript Symbols with an Introduction," in Conversation Analysis: Studies from the First Generation. Editor G H. Lerner written by JZ with conceptual and editorial input from JK, LM, GR, MW, and M-LS.

\section{FUNDING}

Work on this article was supported by funding from the Leibniz Association, Leibniz competition grant K232/2019 awarded to JZ.

\section{ACKNOWLEDGMENTS}

We are grateful to Uwe-Alexander Küttner and the two reviewers for the journal for detailed feedback on an earlier version of this article, which led to conceptual adjustments. We also thank Laurenz Kornfeld, Christina Mack and Jowita Rogowska for editorial input.

(Amsterdam, Philadelphia: John Benjamins Publishing Co), 13-31. doi:10.1075/pbns.125.02jef

Kaiser, J. (2017). »Absolute« Verwendungen von Modalverben im gesprochenen Deutsch: Eine interaktionslinguistische Untersuchung. OraLingua Band 15. Heidelberg: Universitätsverlag Winter. https://ebookcentral.proquest.com/lib/ gbv/detail.action?docID $=5091543$.

Lerner, G. H., and Raymond, G. (2017). "On the Practical Re-intentionalization of Body Behavior," in Enabling Human Conduct: Studies of Talk-In-Interaction in Honor of Emanuel A. Schegloff, Pragmatics \& beyond. New Series (PঊBNS) Volume 273. Editors G Raymond, G H Lerner, and J Heritage (Amsterdam: John Benjamins Publishing Company), 299-313. doi:10.1075/pbns.273.15ler

Liberman, K. (2013). More Studies In Ethnomethodology. SUNY Series in the Philosophy of the Social Sciences. Albany: State University of New York Press.

Malchukov, A. L., and Ogawa., A. (2011). "Towards a Typology of Impersonal Constructions: A Semantic Map Approach," in Malchukov and Siewierska, 19-56.

Malchukov, A., and Siewierska, A. (2011). "Introduction," in Impersonal Constructions: A Cross-Linguistic Perspective. (Amsterdam, Philadelphia: John Benjamins), 1-16. doi:10.1075/slcs.124.01mal

Mondada, L. (2014). Conventions for Multimodal Transcription. https://franz.unibas.ch/ fileadmin/franz/user_upload/redaktion/Mondada_conv_multimodality.pdf.

Orvell, A., Kross, E., and Gelman, S. A. (2017). How "You" Makes Meaning. Science 355 (6331), 1299-1302. doi:10.1126/science.aaj2014

Persson, R. (2015). Indexing One's Own Previous Action as Inadequate: OnahPrefaced Repeats as Receipt Tokens in French Talk-In-Interaction. Lang. Soc. 44 (4), 497-524. doi:10.1017/S004740451500041X

Raymond, C. W., and Stivers, T. (2016). "The Omnirelevance of Accountability," in Accountability in Social Interaction, Foundations of Human Interaction. Editor J D. Robinson (New York, NY: Oxford University Press), 321-354. doi:10.1093/ acprof:oso/9780190210557.003.0011

Rossi, G., and Zinken, J. (2016). Grammar and Social Agency: The Pragmatics of Impersonal Deontic Statements. Language 92 (4). doi:10.1353/lan.2016.0083

Rossi, G. (2018). Composite Social Actions: The Case of Factual Declaratives in Everyday Interaction. Res. Lang. Soc. Interaction 51 (4), 379-397. doi:10.1080/ 08351813.2018.1524562

Schlund, K. (2018). A Unifying Approach to Impersonality in Russian. Z. für Slawistik 63 (1), 120-168. doi:10.1515/slaw-2018-0007

Sidnell, J., and Stivers, T. (2013). "The Handbook of Conversation Analysis," in Blackwell Handbooks in Linguistics (Malden, MA [u.a]: Wiley-Blackwell).

Siewierska, A. (2008). Introduction: Impersonalization from a Subject-Centred vs. Agent-Centred Perspective. Trans. Philological Soc. 106 (2), 115-137. doi:10.1111/j.1467-968X.2008.00211.x

Sorjonen, M-L., Mondada, L., Rossi, G., Weidner, M., and Zinken, J. (2018) . "Building PECII: A Parallel Corpus of Informal Interaction - Issues and Solutions," in 5th International Conference on Conversation Analysis (UK: Loughborough).

Stivers, A. (2004). "No No No" and Other Types of Multiple Sayings in Social Interaction. Hum. Comm Res 30 (2), 260-293. doi:10.1111/j.1468-2958.2004.tb00733.x 
Stukenbrock, A. (2017). "Zur kommunikativen Leistung des generischen "du”-Gebrauchs in der sozialen Interaktion," in Sprache und Beziehung, Linguistik - Impulse \& Tendenzen v.69. Editors A Linke and J Schröter (Berlin/Boston: de Gruyter), 149-182.

Weidner, M. (2018). “Chapter 8. Treating Something as Self-Evident," in Between Turn and Sequence: Turn-Initial Particles across Languages, Studies in Language and Social Interaction v.31. Editors J Heritage and M-L Sorjonen (Amsterdam/Philadelphia: John Benjamins Publishing Company), 225-250. doi:10.1075/slsi.31.08wei

Wittgenstein, L. (1953). Philosophical Investigations. New York: Macmillan.

Zinken, J., Mondada, L., Rossi, G., Sorjonen, M-L., and Weidner, M. (2018). "Using PECII: A Comparative Analysis of Rule Formulation and Enforcement in Board Games," in 5th International Conference on Conversation Analysis (UK: Loughborough).

Conflict of Interest: The authors declare that the research was conducted in the absence of any commercial or financial relationships that could be construed as a potential conflict of interest.
The reviewer, MS, declared a shared affiliation, with one of the authors, M-LS, to the handling editor at the time of the review.

Publisher's Note: All claims expressed in this article are solely those of the authors and do not necessarily represent those of their affiliated organizations, or those of the publisher, the editors and the reviewers. Any product that may be evaluated in this article, or claim that may be made by its manufacturer, is not guaranteed or endorsed by the publisher.

Copyright (c) 2021 Zinken, Kaiser, Weidner, Mondada, Rossi and Sorjonen. This is an open-access article distributed under the terms of the Creative Commons Attribution License (CC BY). The use, distribution or reproduction in other forums is permitted, provided the original author(s) and the copyright owner(s) are credited and that the original publication in this journal is cited, in accordance with accepted academic practice. No use, distribution or reproduction is permitted which does not comply with these terms. 